\title{
Risk Factors for Development of Hypocalcemia in Patients With Cancer Treated With Bone-Modifying Agents
}

Paul S. White, MD¹; Michael Dennis, MD²; Eric A. Jones, $\mathrm{PhD}^{3}$; Janice M. Weinberg, ScD, $\mathrm{MS}^{3}$; and Shayna Sarosiek, MD1

\section{ABSTRACT}

\begin{abstract}
Background: This retrospective analysis describes the prevalence of and risk factors associated with the development of hypocalcemia in patients with cancer receiving bone-modifying agents (BMAs) as supportive care. Patients and Methods: Patients with cancer treated with an intravenous or subcutaneous BMA, including pamidronate, zoledronic acid, or denosumab, at a tertiary care/safety net hospital in 2005 through 2015 were included in this retrospective review. We reviewed the medical records for predictive clinical and laboratory parameters and for patient outcomes. Results: A total of 835 patients with cancer received at least one dose of a BMA during the specified time frame; 205 patients (25\%) developed hypocalcemia of CTCAE grade $\geq 1$ within 8 weeks of BMA initiation, 18 of whom (8.8\%) had grade $\geq 3$, and 3 patients died as a result. Multivariate analysis showed that patients with hematologic malignancy (odds ratio [OR], 1.956; $P=.025)$, bone metastases (OR, 2.443; $P=.017$ ), inpatient status (OR, 2.592; $P<.001)$, and deficient baseline vitamin $D$ levels (OR, 2.546; $P<.023)$ were more likely to develop hypocalcemia. Hypercalcemia before BMA administration (OR, 0.474; $P=$.032) was protective. Conclusions: Certain patient populations, including those with hematologic malignancies and/or bone metastases, warrant closer monitoring of calcium levels while receiving BMAs because of the high rate of hypocalcemia. Low pretreatment vitamin $D$ levels are associated with the development of hypocalcemia. These data support close monitoring of calcium levels in patients with cancer receiving BMAs, in addition to adequate repletion of vitamin $D$ before initiation of BMAs when possible.
\end{abstract}

J Natl Compr Canc Netw 2020;18(4):420-427 doi: $10.6004 /$ jnccn.2019.7370

\footnotetext{
${ }^{1}$ Section of Hematology and Oncology, Department of Medicine, and ${ }^{2}$ Department of Medicine, Boston Medical Center; and ${ }^{3}$ Department of Biostatistics, Boston University School of Public Health, Boston, Massachusetts
}

\section{Background}

Bone-modifying agents (BMAs) are an important component of supportive care for many patients with cancer. These agents include the intravenously administered bisphosphonates pamidronate and zoledronic acid, in addition to denosumab, a subcutaneously administered monoclonal antibody. They are indicated in the treatment and prevention of bone metastases and skeletal-related events and of osteoporosis in patients receiving hormone therapy. ${ }^{1-6}$ These agents are also routinely used for hypercalcemia of malignancy and are part of guideline-directed therapy for patients with multiple myeloma. ${ }^{78}$ In certain patient populations, BMAs can improve pain control, quality of life, and overall survival. ${ }^{9,10}$

Despite the advantages of BMA administration, there are associated risks. Although renal dysfunction and osteonecrosis of the jaw are more commonly known adverse effects of BMAs, additional adverse effects such as hypocalcemia can occur. ${ }^{11,12}$ Prior studies have reported variable rates of hypocalcemia with these agents, ranging from $<1 \%$ to $39 \% .^{3-7,13-15}$ The resulting hypocalcemia is often asymptomatic, but it can also result in more severe clinical events, such as tetany, arrhythmia, seizure, or death. ${ }^{16}$ In this single-institution retrospective study, we sought to identify the prevalence of hypocalcemia and determine the risk factors for development of hypocalcemia in a diverse, multiracial population of patients with cancer receiving treatment with BMAs.

\section{Patients and Methods}

We performed a retrospective review of all individuals who received a BMA at Boston University School of Medicine and Boston Medical Center between January 1 , 2005, and December 31, 2015. This study was approved by the Boston University Medical Center Institutional Review Board. We identified 924 patients with a diagnosis

See JNCCN.org for supplemental online content. 
of a malignancy and a history of BMA administration during the specified time frame. We excluded 4 patients whose malignancy was never confirmed histologically and 85 additional patients for whom the details of BMA administration were unavailable. The remaining 835 patients had a documented malignancy and at least one administration of a BMA recorded at Boston Medical Center. We reviewed the electronic medical records to abstract data regarding the patients' malignancies, bisphosphonate administration, baseline laboratory data, and follow-up laboratory values in order to identify those patients who had hypocalcemia or other complications related to BMA exposure. Baseline laboratory values were included if obtained within 8 weeks before BMA initiation.

Hypocalcemia was defined as a corrected calcium level $<8.5 \mathrm{mg} / \mathrm{dL}$ identified within 8 weeks after any BMA administration. CTCAE version 4.0 criteria were used to further define the grade of hypocalcemia. ${ }^{17}$ Hypercalcemia was defined as a calcium concentration $>10.5 \mathrm{mg} / \mathrm{dL}$. Corrected calcium concentration was calculated using the following formula:

\section{$\mathrm{Ca}($ corr $)=0.8 \times(4-X)+Y$, where $X$ is albumin concentration in $\mathrm{g} / \mathrm{dL}$ and $Y$ is calcium concentration in $\mathrm{mg} / \mathrm{dL}^{18}$}

According to the Endocrine Society guidelines, we used 25-hydroxy vitamin D measurement to assess vitamin D concentration, and considered it to have been checked if the laboratory value was measured within 8 weeks before the first BMA administration, because this is the duration of vitamin $\mathrm{D}$ repletion recommended by the Endocrine Society. ${ }^{19}$ Vitamin D deficiency was defined as a laboratory concentration of 25-hydroxy vitamin $\mathrm{D} \leq 20 \mathrm{ng} / \mathrm{mL}$. We considered a patient to be receiving supplementation if the medical record showed any formulation of calcium and/or vitamin D on the patient's medication list at the time of first BMA administration.

Univariate analyses were performed using the chisquare test (categorical) and Wilcoxon rank-sum test (continuous), with variables in our data set as appropriate. To identify significant predictors of hypocalcemia, we fit a multiple logistic regression model which included only those variables that met the $\leq 0.10$ significance threshold in univariate analyses to control for their combined effects on the outcome of hypocalcemia among study subjects. To identify significant predictors of hypocalcemia among the subset of patients who had vitamin D concentration data available, we followed a similar approach. Thus, we next fit a logistic regression model on these reduced data, again including only variables that met the $\leq 0.10$ significance threshold in univariate analyses. We used stepwise selection with a threshold of entry of 0.30 and a threshold for retention in the final model of 0.35 . We performed correlation analysis to define the association between the percentage of patients with hypocalcemia and vitamin D supplementation over time. For all statistical analyses, a $P$ value $\leq .05$ was considered significant. All analyses were conducted using SAS 9.4 (SAS Institute Inc).

\section{Results}

The patients' baseline characteristics are provided in Table 1. Median patient age was 62 years (range, 2597 years), and 466 patients were female (56\%) and 369 were male (44\%). Of this cohort, 370 (44\%) were black, 305 (37\%) were white, $84(10 \%)$ were Hispanic, 22 (3\%) were Asian, 10 (1\%) were Middle Eastern, and the remaining $44(5 \%)$ were of another ethnicity or unknown. Most patients $(n=518 ; 62 \%)$ received a BMA for bone metastases or lytic bony lesions. Other indications for treatment with a BMA included hypercalcemia of malignancy (23\%), treatment of osteoporosis during cancer treatment $(9 \%)$, or prevention of bone lesions or osteoporosis $(6 \%)$. Most patients $(n=558 ; 67 \%)$ were outpatients at the initiation of BMA; the remainder (33\%) received their first dose while admitted to the hospital. Of the 129 patients with a hematologic malignancy, $112(87 \%)$ had multiple myeloma.

Of the 835 patients, 205 (25\%) developed hypocalcemia after exposure to a BMA, including 88 (43\%) with asymptomatic CTCAE grade 1 and $18(9 \%)$ with grade $\geq 3$ hypocalcemia. Within 8 weeks of BMA administration, 78 patients $(9 \%)$ required hospitalization or intravenous calcium supplementation, $14(2 \%)$ required intensive care unit admission, and $3(0.4 \%)$ died as a result of complications of hypocalcemia; 5 other patients died while hypocalcemic, but their underlying causes of death were unrelated ( 2 of pulmonary emboli, 2 of sepsis, and 1 of acute liver failure).

Univariate analysis showed a statistically significant difference in the development of hypocalcemia based on sex $(P=.04)$, type of BMA used $(P<.01)$, presence or absence of osteoporosis $(P<.01)$, presence or absence of bone metastases $(P<.01)$, and inpatient versus outpatient status $(P=.02)$ (see Table 1$)$. In addition, there was a significant difference in development of hypocalcemia based on the indication for BMA administration $(P<.01)$ and the malignancy type $(P<.01)$. Baseline calcium and 25-hydroxy vitamin D concentrations were significantly different between the patients who developed hypocalcemia and those who did not $(P<.01)$. Vitamin D deficiency was associated with a higher risk of hypocalcemia, whereas calcium/vitamin D supplementation reduced this risk $(P<.01$ and $P=.03$, respectively). 


\section{Table 1. Patient Characteristics}

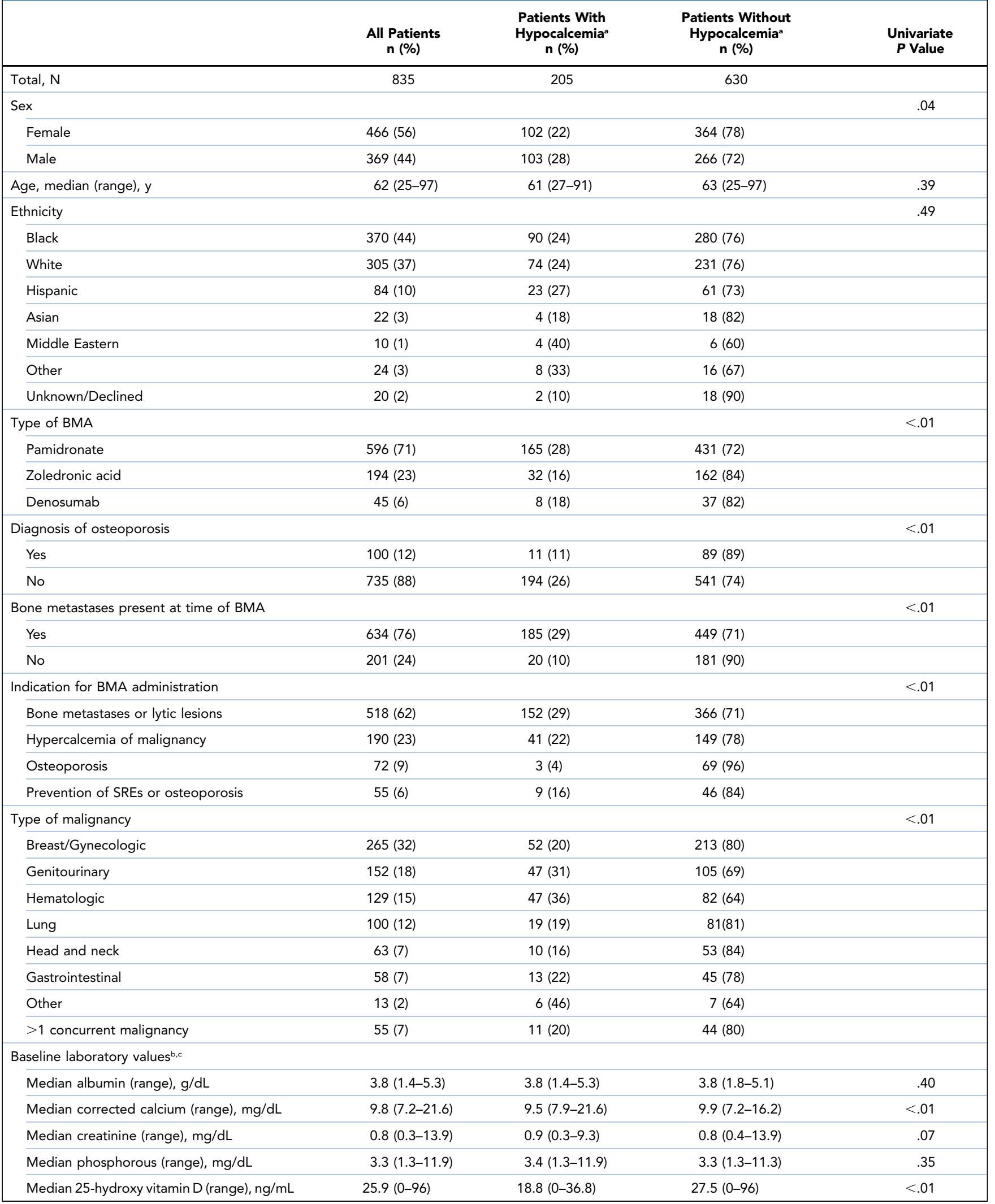




\begin{tabular}{|c|c|c|c|c|}
\hline Vitamin D deficiency $(\leq 20 \mathrm{ng} / \mathrm{mL})$ & & & & $<.01$ \\
\hline Yes & $70(35)$ & $21(30)$ & $49(70)$ & \\
\hline Yes & $250(30)$ & $49(20)$ & $201(80)$ & \\
\hline No & $585(70)$ & $156(27)$ & 429 (73) & \\
\hline Patient status & & & & .02 \\
\hline Inpatient & 277 (33) & $93(34)$ & $184(66)$ & \\
\hline
\end{tabular}

Abbreviations: BMA, bone-modifying agent; SRE, skeletal-related event.

aHypocalcemia defined as corrected calcium level $<8.5 \mathrm{mg} / \mathrm{dL}$.

bBaseline laboratory test values defined as measurements collected $\leq 8$ weeks before BMA.

cThe following numbers of baseline laboratory measurements were missing in the hypocalcemia/no hypocalcemia cohorts, respectively: albumin, $5 / 54$; corrected calcium, 7/66; creatinine, 1/19; phosphorus, 57/285; and 25-hydroxy vitamin D, 169/466.

In multivariate analysis, patients with bone metastases became hypocalcemic significantly more often than did those without (odds ratio [OR], 2.44; $P=.017$ ). Multivariate analysis also showed that patients with hematologic malignancies had a significantly higher rate of hypocalcemia than patients with breast or gynecologic malignancy (OR, 1.96; $P=.025)$ (Table 2). Inpatients receiving BMAs were also more likely to become hypocalcemic $(\mathrm{OR}, 2.59 ; P<.001)$ than those receiving outpatient treatment, and, as expected, a higher corrected calcium concentration before BMA administration reduced the likelihood of developing hypocalcemia (OR, 0.47; $P=.032$ ).

Vitamin D concentrations were not routinely collected in all patients, but $24 \%(n=199)$ of our patients had these checked in the 8 weeks before BMA administration (see Table 1). More than one-third of patients who were checked had vitamin D deficiency $(n=70 ; 35 \%)$. Baseline vitamin $\mathrm{D}$ level reached statistical significance for predicting hypocalcemia after both univariate $(P<.01)$ and multivariate $(P=.023)$ analyses (see Table 1 ; supplemental eTable 1, available with this article at JNCCN.org). In multivariate analysis including only those patients with vitamin D concentrations available before BMA administration $(\mathrm{n}=199)$, creatinine $\geq 1.5 \mathrm{mg} / \mathrm{dL}$ was predictive of hypocalcemia. This subset of patients with deficient vitamin $\mathrm{D}$ concentrations developed hypocalcemia at more than twice the rate of those with sufficient vitamin D (OR, 2.55) (see supplemental eTable 1). Of 250 patients prescribed supplementation, 49 (20\%) still developed hypocalcemia. Over time, there was a statistically significant increase in calcium and vitamin $\mathrm{D}$ supplementation $(P<.001)$ and decline of hypocalcemia rates $(P=.001)$ (Figure 1$)$, with a strong negative correlation between these 2 variables $(r=-0.83 ; P=.002)$.

\section{Discussion}

The benefits of BMAs are many, and they continue to play an important role in the prevention of morbidity in patients with cancer. Despite some prospective trials with hypocalcemia rates $<1 \%$ (Table 3 ), the frequency of hypocalcemia may exceed $25 \%$, as evidenced by this retrospective review. These episodes of hypocalcemia may be associated with serious adverse events, including admission to the intensive care unit and death. ${ }^{1-3,7,13,20-22}$ The aim of this study was to identify risk factors for hypocalcemia in patients with cancer in order to prevent these outcomes.

Case reports have linked vitamin D deficiency to severe hypocalcemia after the use of BMAs, ${ }^{23,24}$ but to our knowledge, this is the first study to show a statistically significant relationship between hypocalcemia and baseline vitamin D levels, which is imperative for calcium absorption and homeostasis. ${ }^{19}$ This illustrates the importance of having sufficient vitamin D levels before initiation of BMAs when possible.

Current guidelines advocate for calcium and vitamin D supplementation during treatment with BMAs. ${ }^{25}$ Vitamin D and calcium supplementation were not routinely recommended by the FDA until 2004 for zoledronic acid, until 2007 for pamidronate, and until 2010 for denosumab (at the time of its FDA approval). ${ }^{26-28}$ Before these years, package inserts for zoledronic acid and pamidronate recommended supplementation of calcium for episodes of symptomatic hypocalcemia after BMA administration. Despite this FDA recommendation, many institutions, such as our own, were not routinely 
Table 2. Multivariate Logistic Regression for Risk Factors of Hypocalcemia With BMAs (N=777)

\begin{tabular}{|c|c|c|c|c|}
\hline Predictor & Odds Ratio & $95 \% \mathrm{Cl}$ & $P$ Value ${ }^{a}$ & $P$ Value ${ }^{b}$ \\
\hline Type of malignancy & & & & .040 \\
\hline Gastrointestinal & 1.028 & $0.471-2.242$ & .945 & \\
\hline Genitourinary & 1.708 & $0.886-3.290$ & .110 & \\
\hline Hematologic & 1.956 & $1.089-3.514$ & .025 & \\
\hline Head and neck & 1.210 & $0.518-2.827$ & .660 & \\
\hline Lung & 0.776 & $0.392-1.535$ & .466 & \\
\hline Other & 3.784 & $0.993-14.420$ & .051 & \\
\hline$>1$ concurrent malignancy & 0.781 & $0.333-1.831$ & .569 & \\
\hline Breast/Gynecologic & Ref & Ref & Ref & \\
\hline First BMA used & & & & 632 \\
\hline Denosumab & 1.285 & $0.480-3.440$ & .618 & \\
\hline Pamidronate & 1.281 & $0.758-2.164$ & .355 & \\
\hline Zoledronic acid & Ref & Ref & Ref & \\
\hline Bone metastases & & & & .017 \\
\hline Bone metastases present & 2.443 & $1.177-5.069$ & .017 & \\
\hline No bone metastases & Ref & Ref & Ref & \\
\hline Osteoporosis & & & & .883 \\
\hline Osteoporosis present & 0.934 & $0.379-2.305$ & .883 & \\
\hline No osteoporosis & Ref & Ref & Ref & \\
\hline Sex & & & & .733 \\
\hline Female & 0.924 & $0.585-1.458$ & .733 & \\
\hline Male & Ref & Ref & Ref & \\
\hline Calcium/Vitamin D supplementation & & & & .700 \\
\hline Supplementation & 0.921 & $0.606-1.399$ & .700 & \\
\hline No supplementation & Ref & Ref & Ref & \\
\hline Indication for BMA administration & & & & .733 \\
\hline Hypercalcemia of malignancy & 1.005 & $0.458-2.205$ & .989 & \\
\hline Osteoporosis & 0.515 & $0.098-2.714$ & .434 & \\
\hline Prevention of SREs & 1.359 & $0.481-3.836$ & .563 & \\
\hline Bone metastasis & Ref & Ref & Ref & \\
\hline Creatinine level & & & & .435 \\
\hline$\geq 1.5 \mathrm{mg} / \mathrm{dL}$ & 1.256 & $0.708-2.230$ & .435 & \\
\hline$<1.5 \mathrm{mg} / \mathrm{dL}$ & Ref & Ref & Ref & \\
\hline Corrected calcium level at baseline & & & & .015 \\
\hline Hypocalcemia $(<8.5 \mathrm{mg} / \mathrm{dL})$ & 2.263 & $0.906-5.655$ & .081 & \\
\hline Hypercalcemia (>10.5 mg/dL) & 0.474 & $0.240-0.938$ & .032 & \\
\hline Normal level (8.5-10.5 mg/dL) & Ref & Ref & Ref & \\
\hline Patient status at time of BMA administration & & & & $<.001$ \\
\hline Inpatient & 2.592 & $1.691-3.972$ & $<.001$ & \\
\hline Outpatient & Ref & Ref & Ref & \\
\hline
\end{tabular}

Statistically significant risk factors are highlighted in bold.

Abbreviations: BMA, bone-modifying agent; SREs, skeletal-related events.

a Overall $P<.001$.

'Type 3 analyses. 


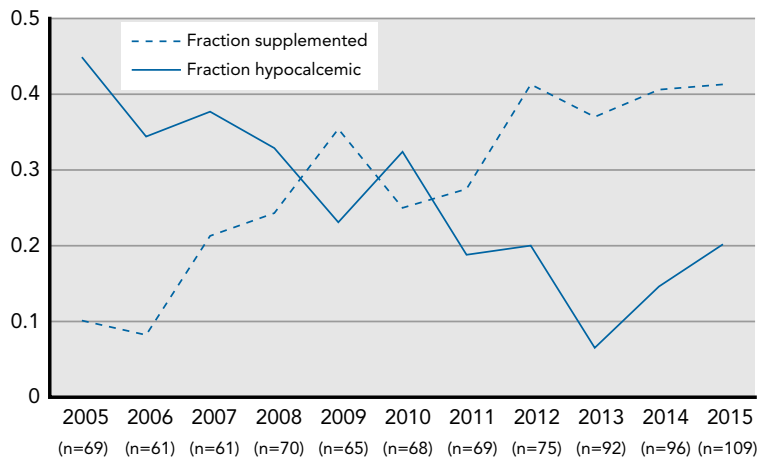

Figure 1. Frequency of calcium/vitamin D supplementation and hypocalcemia over time.

using supplementation. This is likely a contributing factor in the high rate of hypocalcemia seen in this study and highlights the importance of adherence to this recommendation.

Our data confirm that hypocalcemia rates decline with increasing rates of calcium and vitamin D supplementation (see Figure 1). Despite this intervention, 20\% of patients with prescriptions for calcium and/or vitamin D supplementation became hypocalcemic. This may indicate an issue with patient adherence or may show that routine supplementation is not sufficient to prevent hypocalcemia. Therefore, patients continue to need close monitoring after BMA administration, even when vitamin $\mathrm{D}$ and calcium supplementation are given.

Our data suggest that some patient populations may also warrant increased monitoring for hypocalcemia. In our cohort, patients with hematologic cancers had a significantly higher risk of developing hypocalcemia in both univariate and multivariate analyses. The mechanism of the increased risk of hypocalcemia within this subgroup is unclear, but it may be related to the number of additional hypocalcemia risk factors. For example, multiple myeloma affects black patients more than those of other racial or ethnic groups, and black patients have been shown to have a higher rate of vitamin D deficiency. ${ }^{29,30}$ Our cohort consisted of a diverse inner-city population with cancer in a safety-net hospital setting with more racial diversity than in most prior reports on this subject. ${ }^{14,15}$ In addition, chronic renal insufficiency is also a risk factor for hypocalcemia, even without the administration of a BMA, and it is more common in multiple myeloma. ${ }^{16}$ Another retrospective study from Japan found that low creatinine clearance $(<50 \mathrm{~mL} / \mathrm{min})$ was a risk factor for hypocalcemia after denosumab treatment. ${ }^{31}$ Although elevated creatinine was a risk factor for hypocalcemia in our univariate analysis, this was not true in the multivariate analysis, potentially related to the creatinine cutoff chosen for

\begin{tabular}{|c|c|c|}
\hline Trial & BMA & $\begin{array}{c}\text { Patients With } \\
\text { Hypocalcemia, n/N (\%) }\end{array}$ \\
\hline Nussbaum et al,7 1993 & Pamidronate & $3 / 50(6)$ \\
\hline Berenson et al, ${ }^{1} 1996$ & Pamidronate & $1 / 196(<1)$ \\
\hline Hortobagyi et al,,$^{5} 1996$ & Pamidronate & $1 / 185(<1)$ \\
\hline Conte et $\mathrm{al}^{\circ}{ }^{6} 1996$ & Pamidronate & 24/143 (17) \\
\hline Theriault et al, ${ }^{4} 1999$ & Pamidronate & 3/182 (2) \\
\hline \multirow[t]{2}{*}{ Major et al, ${ }^{13} 2001$} & Zoledronic acid & NR/176 (<15) \\
\hline & Pamidronate & NR/99 (<15) \\
\hline \multirow[t]{2}{*}{ Rosen et al, ${ }^{2} 2003^{a}$} & Zoledronic acid & NR/401 (<15) \\
\hline & Pamidronate & NR/205 (<15) \\
\hline Kohno et al, ${ }^{14} 2005$ & Zoledronic acid & 44/114 (39) \\
\hline Smith et al, ${ }^{20} 2009^{a}$ & Denosumab & $1 / 734(<1)$ \\
\hline \multirow[t]{2}{*}{ Stopeck et al, ${ }^{3} 2010^{a}$} & Zoledronic acid & 34/1013 (3) \\
\hline & Denosumab & $56 / 1020(5)$ \\
\hline \multirow[t]{2}{*}{ Fizazi et al, ${ }^{21} 2011^{a}$} & Zoledronic acid & $55 / 951(6)$ \\
\hline & Denosumab & $121 / 950(13)$ \\
\hline \multirow[t]{2}{*}{ Henry et al, ${ }^{22} 2011^{a}$} & Zoledronic acid & $14 / 786(2)$ \\
\hline & Denosumab & $35 / 792(4)$ \\
\hline \multirow[t]{2}{*}{ Himelstein et al, ${ }^{15} 2017^{a}$} & $\begin{array}{l}\text { Zoledronic acid } \\
\text { every } 4 \text { wk }\end{array}$ & 329/866 (38) \\
\hline & $\begin{array}{l}\text { Zoledronic acid } \\
\text { every } 12 \mathrm{wk}\end{array}$ & 298/852 (35) \\
\hline
\end{tabular}

Abbreviations: BMA, bone-modifying agent; NR, not reported.

aVitamin $D$ and calcium supplementation were strongly recommended or required.

this study. Despite this, we recommend tailoring the choice and dose of BMA to the patient's renal function according to the package inserts.

Based on our data, which show a higher risk of hypocalcemia in patients with baseline vitamin D deficiency, we recommend ensuring a sufficient level of vitamin $\mathrm{D}$ before initiating BMAs in patients with cancer when possible. For urgent indications, such as moderate and severe hypercalcemia of malignancy, when waiting to ensure sufficient vitamin D levels before BMA administration is impractical and potentially harmful, concurrent vitamin D and/or calcium supplementation is recommended as stated in the package inserts for these medications. During BMA administration, it is important to continue monitoring calcium levels, even after the initial dose, because previous data have shown late-onset hypocalcemia in some patients receiving BMAs, even after 6 months of treatment. ${ }^{32}$ Although these agents are important in the care of patients with cancer, and although their benefits are many, it is important that clinicians take steps to minimize the possibility of potentially catastrophic adverse effects. 
This study is limited by the inherent issues associated with a single-center retrospective review, including differences in individual practitioner practices in regard to laboratory monitoring and supplementation of vitamin $\mathrm{D}$ and calcium. In addition, our higher rate of hypocalcemia than in prior studies may be partially attributed to closer monitoring of calcium levels, because one-third of this cohort were inpatients at the time of BMA initiation. This could lead to a sampling bias, although most of the patients were treated as outpatients, and therefore this could not explain the $20 \%$ of patients who developed hypocalcemia in the outpatient setting. The increased rate of hypocalcemia in our inpatient population could also reflect a higher acuity of illness, coadministration of other medications that can affect calcium levels, or the existence of other causes of hypocalcemia that are not fully characterized in this study. These data are from a tertiary care safety-net hospital that treats underserved patients who often have multiple comorbidities or uncontrolled medical conditions that may contribute to the medical complexity. It is also worth noting that the baseline calcium concentration in our cohort was lower than in some other published reports, and patients in our cohort were not required to receive calcium and vitamin D supplements.

\section{Conclusions}

This large retrospective review investigated the occurrence of hypocalcemia in a diverse population of patients with cancer treated with pamidronate, zoledronic acid, or denosumab. Our data highlight the importance of close monitoring of calcium levels in patients receiving BMAs, especially those with hematologic malignancy and bone metastases. Due to the increased risk of hypocalcemia in patients with deficient vitamin $\mathrm{D}$ concentrations, we recommend that vitamin $\mathrm{D}$ concentrations be checked and repleted before BMA administration when possible. In patients with urgent indications for BMAs, coadministration of vitamin D supplements should be strongly encouraged for patients with vitamin $\mathrm{D}$ deficiency. Additional studies are needed to further explore specific interventions that can prevent hypocalcemia related to BMAs.

Submitted February 4, 2019; accepted for publication October 14, 2019.

Author contributions: Data collection and analysis: White, Dennis, Sarosiek. Statistical analyses: Jones, Weinberg. Manuscript preparation: White, Dennis, Sarosiek. Critical revision: Jones, Weinberg.

Disclosures: Dr. Weinberg has disclosed that she is a consultant for Janssen. The remaining authors have disclosed that they have not received any financial consideration from any person or organization to support the preparation, analysis, results, or discussion of this article.

Correspondence: Shayna Sarosiek, MD, Section of Hematology and Oncology, Department of Medicine, Boston Medical Center, FGH Building, 1st Floor, 820 Harrison Avenue, Boston, MA 02118. Email: shayna.sarosiek@bmc.org

\section{References}

1. Berenson JR, Lichtenstein A, Porter L, et al. Efficacy of pamidronate in reducing skeletal events in patients with advanced multiple myeloma. N Engl J Med 1996;334:488-493.

2. Rosen LS, Gordon D, Kaminski M, et al. Long-term efficacy and safety of zoledronic acid compared with pamidronate disodium in the treatment of skeletal complications in patients with advanced multiple myeloma or breast carcinoma: a randomized, double-blind, multicenter, comparative trial. Cancer 2003;98:1735-1744.

3. Stopeck AT, Lipton A, Body JJ, et al. Denosumab compared with zoledronic acid for the treatment of bone metastases in patients with advanced breast cancer: a randomized, double-blind study. J Clin Oncol 2010;28:5132-5139

4. Theriault RL, Lipton A, Hortobagyi GN, et al. Pamidronate reduces skeletal morbidity in women with advanced breast cancer and lytic bone lesions: a randomized, placebo-controlled trial. J Clin Oncol 1999;17: 846-854.

5. Hortobagyi GN, Theriault RL, Porter L, et al. Efficacy of pamidronate in reducing skeletal complications in patients with breast cancer and lytic bone metastases. N Engl J Med 1996;335:1785-1792.

6. Conte PF, Latreille J, Mauriac L, et al. Delay in progression of bone metastases in breast cancer patients treated with intravenous pamidronate: results from a multinational randomized controlled trial. J Clin Oncol 1996;14:2552-2559.

7. Nussbaum SR, Younger J, Vandepol CJ, et al. Single-dose intravenous therapy with pamidronate for the treatment of hypercalcemia of malignancy: comparison of 30-, 60-, and 90-mg dosages. Am J Med 1993;95: 297-304.

8. Anderson K, Ismaila N, Flynn PJ, et al. Role of bone-modifying agents in multiple myeloma: American Society of Clinical Oncology clinical practice guideline update. J Clin Oncol 2018;36:812-818.

9. Wardley A, Davidson N, Barrett-Lee $P$, et al. Zoledronic acid significantly improves pain scores and quality of life in breast cancer patients with bone metastases: a randomised, crossover study of community vs hospital bisphosphonate administration. Br J Cancer 2005;92:1869-1876.
10. Morgan GJ, Davies FE, Gregory WM, et al. First-line treatment with zoledronic acid as compared with clodronic acid in multiple myeloma (MRC Myeloma IX): a randomised controlled trial. Lancet 2010;376: 1989-1999.

11. Bamias A, Kastritis E, Bamia C, et al. Osteonecrosis of the jaw in cancer after treatment with bisphosphonates: incidence and risk factors. J Clin Oncol 2005;23:8580-8587.

12. Raje N, Terpos E, Willenbacher W, et al. Denosumab versus zoledronic acid in bone disease treatment of newly diagnosed multiple myeloma: an international, double-blind, double-dummy, randomised, controlled, phase 3 study. Lancet Oncol 2018;19:370-381.

13. Major $\mathrm{P}$, Lortholary $\mathrm{A}$, Hon J, et al. Zoledronic acid is superior to pamidronate in the treatment of hypercalcemia of malignancy: a pooled analysis of two randomized, controlled clinical trials. J Clin Oncol 2001;19: 558-567.

14. Kohno N, Aogi K, Minami H, et al. Zoledronic acid significantly reduces skeletal complications compared with placebo in Japanese women with bone metastases from breast cancer: a randomized, placebo-controlled trial. J Clin Oncol 2005;23:3314-3321.

15. Himelstein AL, Foster JC, Khatcheressian JL, et al. Effect of longerinterval vs standard dosing of zoledronic acid on skeletal events in patients with bone metastases: a randomized clinical trial. JAMA 2017. 317:48-58.

16. Fitzpatrick LA. The hypocalcemic states. In: Coe FL, Favus MJ, eds. Disorders of Bone and Mineral Metabolism, 2nd ed. Philadelphia, PA: Lippincott Williams \& Wilkins; 2002:568-588.

17. Common Terminology Criteria for Adverse Events (CTCAE), Version 4.0 Bethesda, MD: NCl; 2009

18. Payne RB, Little AJ, Williams RB, et al. Interpretation of serum calcium in patients with abnormal serum proteins. Br Med J 1973;4:643-646.

19. Holick MF, Binkley NC, Bischoff-Ferrari HA, et al. Evaluation, treatment, and prevention of vitamin D deficiency: an Endocrine Society clinical practice guideline. J Clin Endocrinol Metab 2011;96: 1911-1930. 
20. Smith MR, Egerdie B, Hernández Toriz N, et al. Denosumab in men receiving androgen-deprivation therapy for prostate cancer. N Engl J Med 2009;361:745-755.

21. Fizazi K, Carducci M, Smith M, et al. Denosumab versus zoledronic acid for treatment of bone metastases in men with castration-resistant prostate cancer: a randomised, double-blind study. Lancet 2011;377: 813-822.

22. Henry DH, Costa L, Goldwasser F, et al. Randomized, double-blind study of denosumab versus zoledronic acid in the treatment of bone metastases in patients with advanced cancer (excluding breast and prostate cancer) or multiple myeloma. J Clin Oncol 2011;29: 1125-1132.

23. Breen TL, Shane E. Prolonged hypocalcemia after treatment with zoledronic acid in a patient with prostate cancer and vitamin D deficiency. J Clin Oncol 2004;22:1531-1532.

24. Maalouf NM, Heller HJ, Odvina CV, et al. Bisphosphonate-induced hypocalcemia: report of 3 cases and review of literature. Endocr Pract 2006; 12:48-53.
25. Gralow JR, Sybil Biermann J, Farooki A et al. NCCN Task Force Report: bone health in cancer care. J Natl Compr Canc Netw 2013;11(Suppl 3) S1-50; quiz S51.

26. Zometa [package insert]. East Hanover, NJ: Novartis; 2004

27. Aredia [package insert]. East Hanover, NJ: Novartis; 2007

28. Prolia [package insert]. Thousand Oaks, CA: Amgen; 2010.

29. Harris SS, Dawson-Hughes B. Seasonal changes in plasma 25-hydroxyvitamin D concentrations of young American black and white women. Am J Clin Nutr 1998;67:1232-1236.

30. Taksler GB, Cutler DM, Giovannucci E, et al. Vitamin D deficiency in minority populations. Public Health Nutr 2015;18:379-391.

31. Okada N, Kawazoe K, Teraoka K, et al. Identification of the risk factors associated with hypocalcemia induced by denosumab. Biol Pharm Bull 2013;36:1622-1626.

32. Body JJ, Bone HG, de Boer RH, et al. Hypocalcaemia in patients with metastatic bone disease treated with denosumab. Eur J Cancer 2015;51: 1812-1821

\section{See JNCCN.org for supplemental online content.}

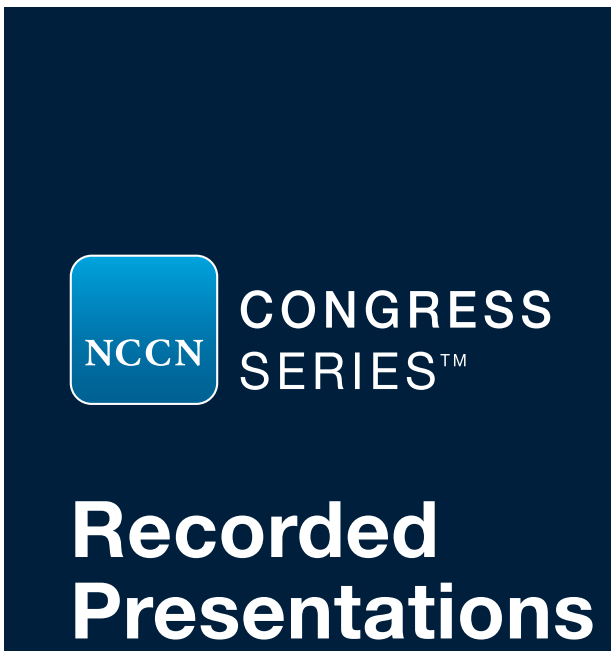

education.nccn.org/breast

\section{BREAST CANCER}

with Updates from the 2019 San Antonio

Breast Cancer Symposium

- Genetics/Familial Risk Assessment: Controversies and Evolving Principles

- Adjuvant and Neoadjuvant Therapies for Early Stage Disease, Including SABCS Updates

- Surgical Management, Including SABCS Updates

- Is There a Role for Proton Therapy?

- Principles of Breast Reconstruction after Surgery

- Biomarker Assays for Treatment Selection of Advanced Disease

- Management of Metastatic Disease, Including SABCS Updates

- Management of Toxicities with Targeted Therapies

- Management of Rare Breast Cancers 
Supplemental online content for:

\section{Risk Factors for Development of Hypocalcemia in Patients With Cancer Treated With Bone-Modifying Agents}

Paul S. White, MD; Michael Dennis, MD; Eric A. Jones, PhD; Janice M. Weinberg, ScD, MS; and Shayna Sarosiek, MD

J Natl Compr Canc Netw 2020;18(4):420-427

eTable 1: Multivariate Logistic Regression for Risk Factors of Hypocalcemia With BMAs Among Patients With Available Baseline Vitamin D Levels 


\begin{tabular}{|c|c|c|c|c|}
\hline Predictor & Odds Ratio & $95 \% \mathrm{Cl}$ & $P$ Value & $P$ Value $^{a}$ \\
\hline Bone metastases & & & & .154 \\
\hline Bone metastases present & 2.233 & $0.740-6.738$ & .154 & \\
\hline No bone metastases & Ref & Ref & Ref & \\
\hline Osteoporosis & & & & .244 \\
\hline Osteoporosis present & 0.276 & $0.032-2.404$ & .244 & \\
\hline No osteoporosis & Ref & Ref & Ref & \\
\hline Creatinine level & & & & .008 \\
\hline$\geq 1.5 \mathrm{mg} / \mathrm{dL}$ & 3.952 & $1.433-10.899$ & .008 & \\
\hline$<1.5 \mathrm{mg} / \mathrm{dL}$ & Ref & Ref & Ref & \\
\hline Corrected calcium level at baseline & & & & .173 \\
\hline Hypocalcemia ( $<8.5 \mathrm{mg} / \mathrm{dL})$ & 3.023 & $0.358-25.549$ & .310 & \\
\hline Hypercalcemia (>10.5 mg/dL) & 0.456 & $0.154-1.351$ & .156 & \\
\hline Normal level (8.5-10.5 mg/dL) & Ref & Ref & Ref & \\
\hline Patient status at time of BMA administration & & & & .091 \\
\hline Inpatient & 2.256 & $0.879-5.785$ & .091 & \\
\hline Outpatient & Ref & Ref & Ref & \\
\hline Baseline vitamin D level & & & & .023 \\
\hline$<20 \mathrm{ng} / \mathrm{mL}$ & 2.546 & $1.136-5.706$ & .023 & \\
\hline$\geq 20 \mathrm{ng} / \mathrm{mL}$ & Ref & Ref & Ref & \\
\hline
\end{tabular}

Statistically significant risk factors are highlighted in bold.

Abbreviation: BMA, bone-modifying agent.

aType 3 analyses. 